\title{
Application of neural networking for calculation of permeability parameters in shaly formations using well logging and core data.
}

\author{
Soares, Y.; Nogueira, S.; Carrasco, A. UFF/TEQ - Niterói, RJ
}

Copyright 2019, SBGf - Sociedade Brasileira de Geofísica

This paper was prepared for presentation during the $16^{\text {th }}$ International Congress of the Brazilian Geophysical Society held in Rio de Janeiro, Brazil, August 19-22, 2019.

Contents of this paper were reviewed by the Technical Committee of the $16^{\text {th }}$ International Congress of the Brazilian Geophysical Society and do not necessarily represent any position of the SBGf, its officers or members. Electronic reproduction or storage of any part of this paper for commercial purposes without the written consent of the Brazilian Geophysical Society is prohibited.

\begin{abstract}
Neural networks can learn complex non-linear relationship, even when the input information is noise and less precise. It has made advances in classification, pattern recognition and process modeling. It is well know that shaly formations gives some effects on the reservoir as reduction in storage capacity by reducing effective porosity and reduces the ability to transmit fluids by lowering permeability. The presence of clay in a reservoir has two effects on petrophysical logs: lowers resistivity and it causes the porosity logs (sonic, neutron and density) to generally record too high a porosity (Asquith, 1990). For neural application, the back propagation network was used, taking as reference the well logging and core data from three wells of Namorado Field of Campos Basin (Brazil) Finally, and error analysis was done taking the permeability values obtained from cores as reference.
\end{abstract}

\section{Introduction}

Petrophysical characterization is an important aspect in petroleum engineering. This data, especially permeability, can be obtained from well logging, cores and drill stem test. Knowledge of permeability is important and its determination is an active research area in petroleum industry, as there is no direct formula for calculation of permeability from logs. The conventional methods for permeability calculation are core analysis and drill stem tests. However, these methods have some limitations and expensive (Kohli \& Arora, 2014).

Other indirect method used to know this parameter is the geophysical logging, which is performed in almost all wells, either during or immediately after the drilling process. Coring is another technique used but generally done in some wells in a new area and in some specific depth intervals. Although expensive, it would provide valuable information. In order to know this parameter, the computational technique of artificial neural networks was used.

Artificial neural networks are computational devices whose conception has been motivated by our current knowledge of biological nervous systems, and offers an alternative to the traditional computational approach based on sequential and algorithmic processing (Shokir et al., 2006).

The back propagation neural network is probably the most well-known and widely used feedforward neural network system. The term back-propagation refers to the training method by which the connection weights of the network are adjusted. During operation, all information flow is feedforward. Figure 1 shows the basic structure of the backpropagation network.

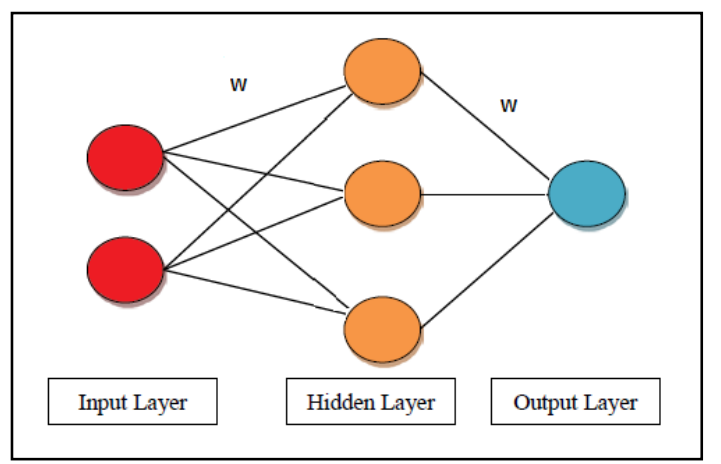

Figure 1. Basic structure of a back - propagation network (Kohli \& Arora, 2014)

In this Figure, a group of neurons, called input neurons, receive information from the real world. These neurons are interconnected to another layer, called the hidden layer, and they, in turn, are interconnected to output neurons. Each interconnection has a numerical value, called weight $(\mathrm{W})$; depending on the weights, different input patterns can result in the firing of one or more output neurons. Through training, the output neurons are taught to give the correct answer. The output patter is them compared to the desired output, and an error signal is computed for each output unit (Ali, 1994).

This technique was applied using the well logs and core information from three wells of the Namorado Field. According to Guardado et al. (1990), the Namorado Field was discovered in 1975, and is located in the central part of the Campos Basin, about $80 \mathrm{~km}$ from the coast of the state of Rio de Janeiro, in water depth of $110-250 \mathrm{~m}$. The oil accumulation is controlled by turbidites, sandstones and structural attributes. The reservoir is sealed by a mixture of limestone and clay, with hemipelagic shale sequence. The Namorado sandstone consists of several layers of turbidites sands with alternate shale layers. These sandstones are coarse grained with locally arkose sections and conglomerates (Barboza, 2005). 


\section{Method}

The following well logging geophysical data was considerate as input for neural network application: gamma ray (GR), density (RHOB), neutron (NPHI), sonic (DT) and resistivity (ILD) logs. Also was included core permeability data. These information was taken for three wells: 3NA 002 RJS, 3NA 004RJS and 4RJ 0042RJS.

As a first stage, a preliminary analysis in calculating shaliness using GR and the joint of density and neutron for these three wells. The gamma ray clay indicator VCLGR (green curve of the fifth track of figures 2, 3 and 4) was calculated using the following equation 1 :

$$
V c l G r=\frac{G r-G r C l e a n}{\text { GrClay }- \text { GrClean }}(\text { Eq.1) }
$$

The double clay indicator work on the principle of defining a clean line and a clay point. The clay volume (VCLND red curve of figures 2, 3 and 4) is calculated as the distance the input data falls between the clay point and the clean line. The following equation 2 was used:

$V c l N D=\frac{\left(D_{C 2}-D_{C 1}\right) \times\left(N-N_{C 1}\right)-\left(D-D_{C 1}\right) \times\left(N_{C 2}-N_{C 1}\right)}{\left(D_{C 2}-D_{C 1}\right) \times\left(N_{S}-N_{C 1}\right)-\left(D_{S}-D_{C 1}\right) \times\left(N_{C 2}-N_{C 1}\right)}$

where $\mathrm{D}_{\mathrm{c} 1}, \mathrm{~N}_{\mathrm{C} 1}, \mathrm{D}_{\mathrm{c} 2}$ and $\mathrm{N}_{\mathrm{c} 2}$ are the density and neutron values for the two ends of the clean line.

Based on these results, the log was divided in different 5 zones, as shown in Figure 2, 3 e 4.

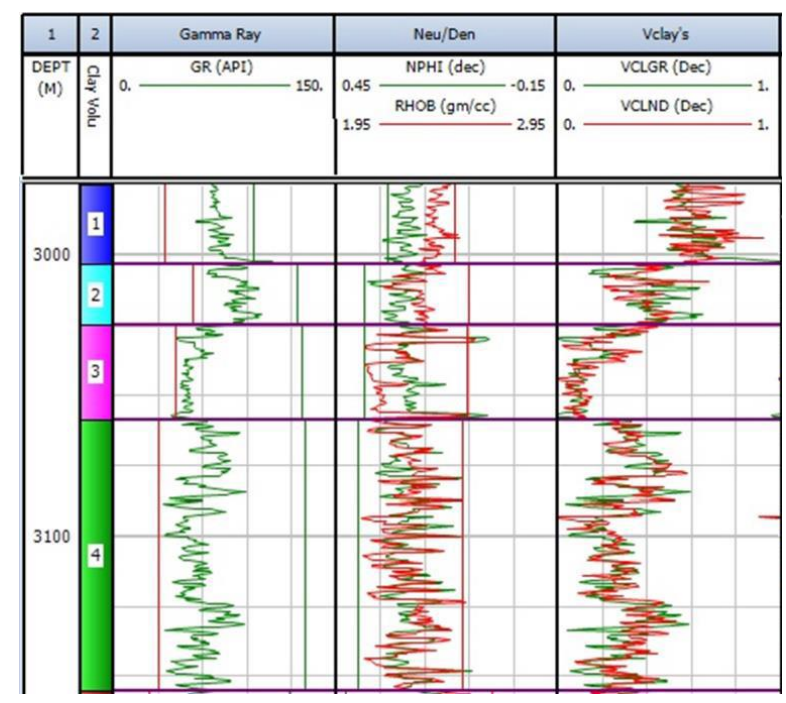

Figure 2. Shaliness calculation for 3NA 002 RJS

In Figure 2, zones 1, 2 and 3 are characterized for having a decreasing shaliness from top to $3050 \mathrm{~m}$. Below this zones, there is an heterogeneous distribution of clay. For this well was taken 30 core data available for permeability and corresponds to an interval of $3044-3054$ (zone 3 and upper part of zone 4).

For well 4RJ 0042 RJ in Figure 3, there was defined 4 zones taking the shaliness as reference. Zones 1 and 4 have lower values of shaliness. Zone 2 has a highest value on the top and zone 3 shows different values from those parameters: VCLGR and VCLND, showing presence of arkose elements. Core data corresponds to 15 values of permeability to the interval of $3131-3140 \mathrm{~m}$ belonging to the zone 4 .

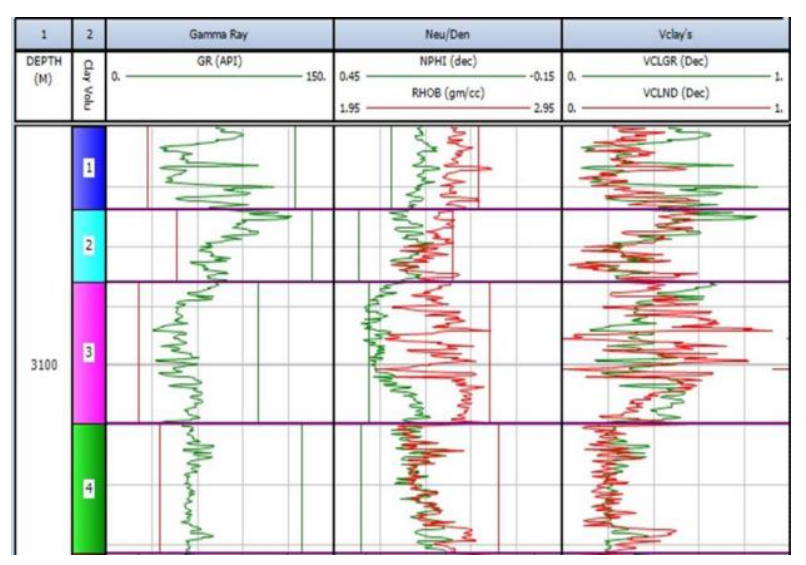

Figure 3. Shaliness calculation for 4RJ $0042 \mathrm{RJ}$

The same procedure was done with data from the well called 3NA 004RJS and the results are shown in the Figure 4.

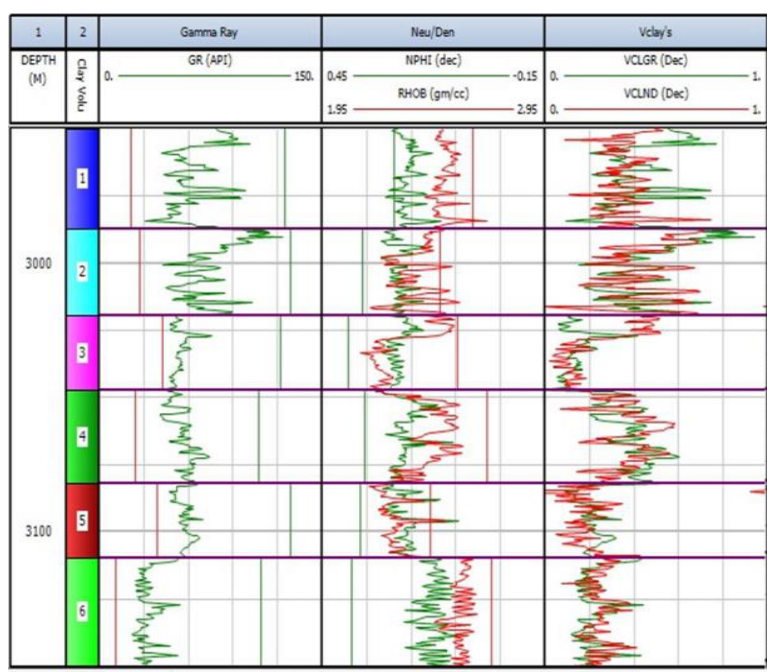

Figure 4. Shaliness calculation for 3NA 004 RJS

In Figure 4 the interval logged was divided into 6 zones. Zones 1 and 2 having the higher values of shaliness, Zones 3, 5 and 6 the lower values and intermediate values for zone 4. Core data corresponds to 19 measurements from the 3037 - $3053 \mathrm{~m}$ depth and located in zone 3.

After this previous task, this information was used for neural network application, using the back propagation method. For each well was chosen the best suit of geophysical log in order to get the minimum error according 
the obtained results. For this work, the Interactive Petrophysics Software was used as interpretation tool.

\section{Results}

The first case to be studied was made with the well 3NA 002 RJS, as shown in Figure 5.

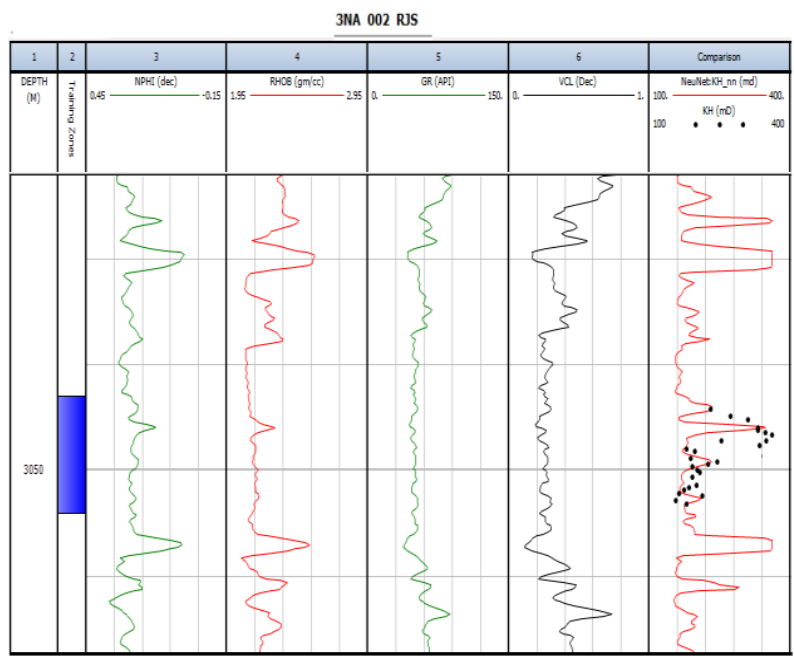

Figure 5. Permeability curve obtained for 3NA 002 RJS

In this Figure the well log curves chosen was the neutron (NPHI on track 3), density (RHOB on track 4), gamma ray (GR on track 5), and the result from the shaliness calculation (VCL on track 6).

\begin{tabular}{cccc}
\hline DEPTH $(\mathrm{m})$ & REAL $(\mathrm{mD})$ & CURVE $(\mathrm{mD})$ & ERROR \\
\hline $\mathbf{3 0 4 4 , 2}$ & 231,2 & 232,6 & 0,006 \\
$\mathbf{3 0 4 4 , 8}$ & 273,6 & 168,5 & 0,384 \\
$\mathbf{3 0 4 5 , 2}$ & 310,7 & 163,5 & 0,473 \\
$\mathbf{3 0 4 6}$ & 330,6 & 347,3 & 0,048 \\
$\mathbf{3 0 4 6 , 6}$ & 361,2 & 198,1 & 0,45 \\
$\mathbf{3 0 4 7 , 2}$ & 252,8 & 181,1 & 0,283 \\
$\mathbf{3 0 4 7 , 4}$ & 358,6 & 189,7 & 0,470 \\
$\mathbf{3 0 4 7 , 6}$ & 334,4 & 182,1 & 0,455 \\
$\mathbf{3 0 4 8}$ & 179,6 & 177,4 & 0,012 \\
$\mathbf{3 0 4 8 , 2}$ & 197,7 & 162,2 & 0,179 \\
$\mathbf{3 0 4 8 , 4}$ & 358,5 & 198,7 & 0,445 \\
$\mathbf{3 0 4 8 , 6}$ & 344,4 & 212,7 & 0,382 \\
$\mathbf{3 0 4 8 , 8}$ & 187,8 & 214,9 & 0,126 \\
$\mathbf{3 0 4 9 , 2}$ & 244,4 & 231,7 & 0,051 \\
$\mathbf{3 0 4 9 , 4}$ & 224,8 & 221,7 & 0,013 \\
$\mathbf{3 0 4 9 , 6}$ & 191,3 & 202,4 & 0,054 \\
$\mathbf{3 0 5 0}$ & 202,4 & 178,5 & 0,118 \\
$\mathbf{3 0 5 0 , 2}$ & 206,8 & 171,8 & 0,169 \\
$\mathbf{3 0 5 0 , 6}$ & 191,1 & 168,6 & 0,117 \\
$\mathbf{3 0 5 1 , 4}$ & 200,3 & 168 & 0,161 \\
$\mathbf{3 0 5 1 , 6}$ & 164,6 & 184,4 & 0,107 \\
$\mathbf{3 0 5 1 , 8}$ & 174,7 & 164,5 & 0,058 \\
$\mathbf{3 0 5 2 , 2}$ & 163 & 172,5 & 0,055 \\
$\mathbf{3 0 5 2 , 8}$ & 157 & 204,8 & 0,233 \\
$\mathbf{3 0 5 3}$ & 328,3 & 187,3 & 0,429 \\
$\mathbf{3 0 5 3 , 2}$ & 180,2 & 176,7 & 0,019 \\
$\mathbf{3 0 5 3 , 4}$ & 296,5 & 174,4 & 0,411 \\
$\mathbf{3 0 5 3 , 6}$ & 151,1 & 176,5 & 0,143 \\
\hline
\end{tabular}

Table 1. Comparison between permeability core data and values predicted for 3NA 002 RJS
Track 7 shows the permeability core values (black dots) and the curve in red is the result values of permeability. Track 2 shows a blue zone as the interval training depth chosen by getting the predictive responses.

Resistivity and sonic log were considered in the initial stage of the simulation, however these logs were discarded because the results showed greater error in their responses. The resistivity effect on the preliminary results can be explained by the irregular presence of dispersed clay causing an increasing in conductivity values, and by other hand, the responses obtained by including sonic log is because shale are sensitive to the effect of compaction. As mentioned earlier, core data belongs to the interval $3044-3054 \mathrm{~m}$, from zone 3 and 4 and these values are shown in the second column of Table 1. This table shows a comparison between real and predicted data of permeability, and the error calculated for each real data core. The highest error is located in the top of the training zone, possibly because the training zone are located in two different zones.

For the second case, the results obtained for the well 4RJ $0042 \mathrm{RJ}$ is shown in Figure 6.

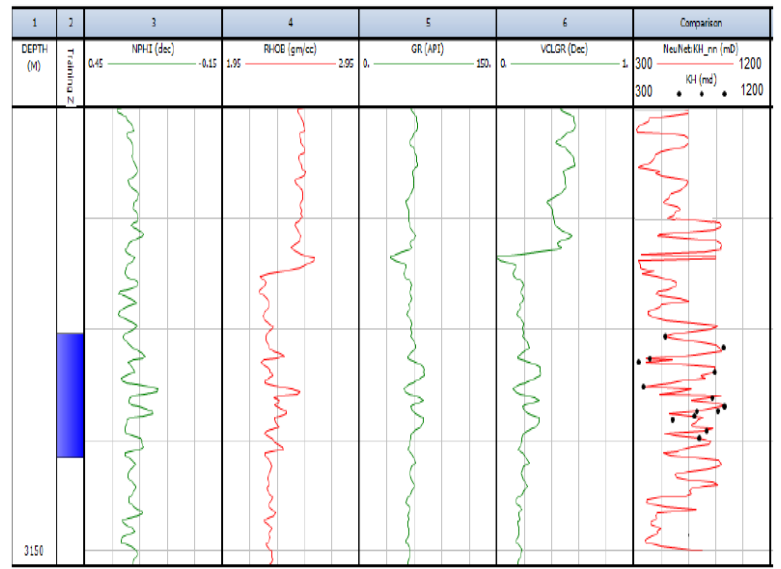

Figure 6. Permeability curve obtained for well 0042RJ

In this well, as in the previous case, the resistivity and sonic log were omitted and chosen NPHI, RHOB, GR logs and VCL results and core information for training data. Track 7 shows the permeability core values (black dots) and the red curve is the predicted values of permeability after using neural network. Track 2 shows a blue zone as the interval training depth. Core data corresponds to the interval $3131-3140 \mathrm{~m}$ and in this case, all core values belong to the zone 4 . In this case, comparing the permeability values show a minimal error between them and the values are consistent in the adjacent zones. Numerically this fact is observed in the Table 2 and this consistency in the results might be explained because the core values belong to the same zone. 


\begin{tabular}{cccc}
\hline DEPTH $(\mathrm{m})$ & REAL $(\mathrm{mD})$ & CURVE $(\mathrm{mD})$ & ERROR \\
\hline $\mathbf{3 1 3 0 , 6}$ & $539, \mathbf{3}$ & 536,1 & 0,005 \\
$\mathbf{3 1 3 1 , 6}$ & 881,9 & 859,5 & 0,025 \\
$\mathbf{3 1 3 2 , 6}$ & 444,7 & 421 & 0,053 \\
$\mathbf{3 1 3 3}$ & 377,4 & 420,4 & 0,102 \\
$\mathbf{3 1 3 3 , 8}$ & 832,9 & 834,4 & 0,001 \\
$\mathbf{3 1 3 5 , 2}$ & 408,4 & 406,2 & 0,005 \\
$\mathbf{3 1 3 6 , 2}$ & 817,1 & 790,9 & 0,032 \\
$\mathbf{3 1 3 7}$ & 890,4 & 869,5 & 0,023 \\
$\mathbf{3 1 3 7 , 4}$ & 727,4 & 721,9 & 0,007 \\
$\mathbf{3 1 3 7 , 8}$ & 709,4 & 702,4 & 0,009 \\
$\mathbf{3 1 3 8 , 2}$ & 877,8 & 735,8 & 0,161 \\
$\mathbf{3 1 3 8 , 4}$ & 579,5 & 718,6 & 0,193 \\
$\mathbf{3 1 3 9 , 2}$ & 781,5 & 763,4 & 0,023 \\
$\mathbf{3 1 3 9 , 8}$ & 737,5 & 743,8 & 0,008 \\
\hline
\end{tabular}

Table 2. Comparison between permeability core data and values predicted for $4 \mathrm{RJ} 0042 \mathrm{RJ}$

Finally, neural network was applied in 3NA004RJS data for the same group of geophysical log: NPHI, RHOB, GR logs and VCL results, and core data of 19 values of permeability, corresponding to the zone 3 , as shown in Figure 7

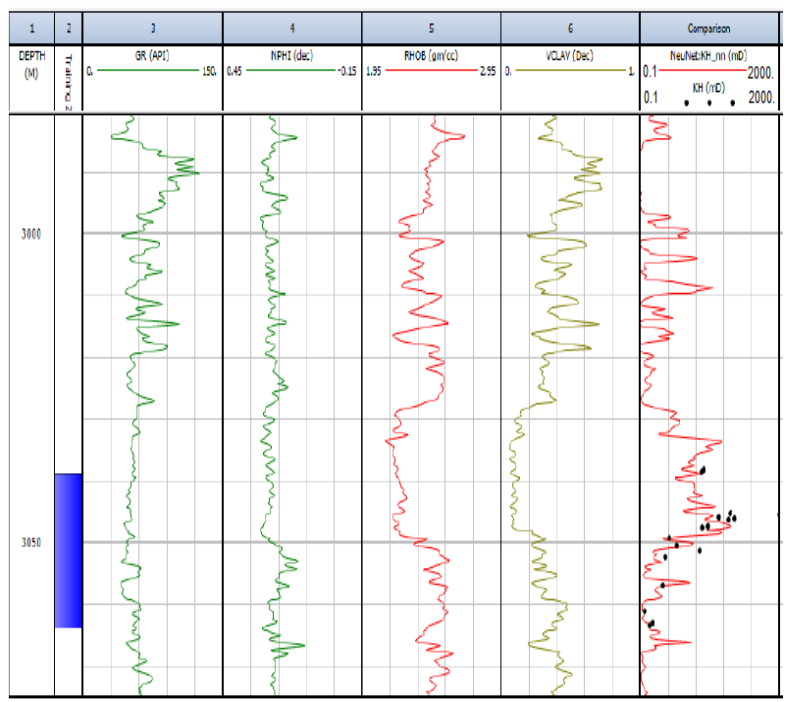

Figure 7. Permeability curve obtained for well 3NA004RJS

Core data corresponds to an interval $3037-3053 \mathrm{~m}$ and these values belong to the zone 3 obtained from preliminary interpretation. In this case, permeability data core and neural network result shows good agreement in their responses. Table 3 shows this comparison between these values this consistency in the results might be explained because the core values belong to the same zone. This zone is characterized by having low values of shaliness with high values of permeability. For other values predicted there is a good consistency in their results when shaliness has high values.

\begin{tabular}{cccc}
\hline DEPTH $(\mathrm{m})$ & REAL $(\mathrm{mD})$ & CURVE $(\mathrm{mD})$ & ERROR \\
\hline $\mathbf{3 0 3 6 , 8}$ & 1252,3 & 790,3 & 0,368 \\
$\mathbf{3 0 3 7}$ & 1134,1 & 970,8 & 0,143 \\
$\mathbf{3 0 3 7 , 6}$ & 1189,6 & 1219,9 & 0,024 \\
$\mathbf{3 0 3 8}$ & 1020,8 & 794,3 & 0,221 \\
$\mathbf{3 0 3 8 , 4}$ & 971 & 960,8 & 0,010 \\
$\mathbf{3 0 4 3 , 2}$ & 1656,9 & 1669,8 & 0,007 \\
$\mathbf{3 0 4 4 , 4}$ & 1455,2 & 1746,2 & 0,166 \\
$\mathbf{3 0 4 4 , 8}$ & 1629,2 & 1272,4 & 0,219 \\
$\mathbf{3 0 4 5 , 2}$ & 1433,5 & 1553,8 & 0,077 \\
$\mathbf{3 0 4 5 , 4}$ & $\mathbf{2 2 2 6 , 5}$ & 1492,4 & 0,329 \\
$\mathbf{3 0 4 5 , 8}$ & 1251,2 & 1567,1 & 0,201 \\
$\mathbf{3 0 4 6}$ & 1499,5 & 1495,7 & 0,002 \\
$\mathbf{3 0 4 6 , 2}$ & 1410,5 & 1516,9 & 0,070 \\
$\mathbf{3 0 4 7 , 2}$ & 1083,3 & 2102,5 & 0,484 \\
$\mathbf{3 0 4 7 , 4}$ & 982,8 & 2064,7 & 0,523 \\
$\mathbf{3 0 4 9 , 2}$ & 462,8 & 985,4 & 0,530 \\
$\mathbf{3 0 5 0 , 4}$ & 585,6 & 815 & 0,281 \\
$\mathbf{3 0 5 1 , 2}$ & 950 & 1248,3 & 0,238 \\
$\mathbf{3 0 5 3 , 2}$ & 1003,9 & 1271,4 & 0,210 \\
\hline & & &
\end{tabular}

Table 3. Comparison between permeability core data and values predicted for 3NA004RJS

\section{Conclusions}

The results were satisfactory for all wells studied even when shaly formations are present. Thus, the application of neural network technique proved to be efficient for its application in shaly formations. Analyzing for each well, in the first case (3NA 002RJS), results based on table 1 showed an average error of 0.209 , a value that can be considered adequate, even the sample values corresponding to different zones according to the preliminary interpretation, with presence arkose and showing some differences if comparing with the results obtained. For the second case (well 4RJ 0042RJ) shows a good fit with results obtained, given an average error of 0,046 (from table 2) and having high permeability values. In the last case, considering the well 3NA004RJS, the average error was 0,216 and core data correspond to an interval of low permeability (low presence of clay) but with a larger range of permeability values and this fact was not a limitation for the application of the neural network technique.

\section{Acknowledgement}

To the Federal Fluminense University (UFF) by infraesstructure. ANP (National Petroleum Agency) for data base and Senergy Software by the academic license of Interactive Petrophysics (IP).

\section{References}

Ali, J. K. Neural Networks: A New Tool for the Petroleum Industry. SPE 27561. 1994.

Asquith, G. B. Log Evaluation of Shaly Sandstone: A Practical Guide. American Association of Petroleum Geologists. 1990. 
Barboza, E. G. Análise Estratigráfica de Campo Namorado (Bacia de Campos), com base na Interpretação Sísmica Tridimensional. Tese de doutorado, Curso de pós-graduação em Geociências. IFRGS, 2005

Guardado, L. R., Gamboa, L. A. P. \& Lucchesi, C. T., Petroleum Geology of the Campos Basin, Brazil, a Model for a Producing Atlantic Type Basin. AAPG Memoir 48, American Association of Petroleum Geologists, Tulsa, p3-79, 1990.

Kohli, A. \& Arora, P. Application of Artificial Neural Networks for Well Logs. IPTC 17475. 2014.

Shokir, E.; Alsughayer, A.; Atteq, Al. Permeability Estimation from well log responses. Journal of Canadian Petroleum Technology. Volume 45, No 11. 2006. 